\title{
Performance, Inclusion and Excellence: An Index of Educational Achievements for PISA
}

\author{
Antonio Villar \\ Universidad Pablo de Olavide \& Ivie
}

\begin{abstract}
This paper proposes an elementary multidimensional index that summarizes three relevant aspects of the educational achievements, out of the data provided by the PISA Reports. The three aspects considered are: performance, inclusiveness, and excellence, and will be approximated by the average scores and the distribution of outcomes in the different levels of proficiency. The Index of Educational Achievements (IEA) is the geometric mean of the normalised values of those three variables. We analyse the distribution of the variables that approach those three aspects and the resulting index, relative to the corresponding average test scores of the OECD countries. This index provides a much wider discrimination power than the mere comparison of the average scores, as the distribution of the three variables is very different.
\end{abstract}

Keywords: Education, PISA, multidimensional measurement, performance, inclusiveness, excellence, OECD.

\section{INTRODUCTION}

This paper aims at providing an elementary indicator of educational performance, using PISA data, which goes beyond the consideration of the average test scores by incorporating other relevant aspects of the educational outcomes.

PISA is the acronym of the Programme for International Student Assessment (PISA). This is a study, coordinated by the OECD, which provides the broadest dataset for the evaluation of schoolchildren performance and the characteristics of their schooling and family environment. It is a triennial worldwide test of 15-year-old schoolchildren's scholastic performance. The aim the PISA is to test and compare schoolchildren's performance across the world, with a view to improving educational methods and outcomes. Students also are asked to answer a questionnaire on their personal background, their learning habits, their attitudes towards studying, and their engagement and motivation. As a result, PISA reports provide an extensive and extremely rich profile of knowledge and skills among 15-year-olds, as well as contextual indicators relating performance results to student and school characteristics. ${ }^{1}$

There are many aspects that can be analysed with the rich database that PISA provides, some of which are already carefully dealt with in the PISA reports. Our focus here is to find a way of synthesising some basic traits of the educational achievements of those countries participating in the PISA survey in the field of science, which is the main subject of the 2015 wave. To do so

\footnotetext{
1 PISA surveys started in 2000 with the aim of evaluating the students' ability, about the end of compulsory education, in three different domains: reading, mathematics and science. Every period of assessment specialises in one particular domain, but it also tests the other two. The subject specialisation is rotated through each PISA wave. Therefore, although information for any of the domains is available in all waves, there are some differences in the pieces of information obtained for a specific domain in each occasion. The 2015 report has focused on science.
} 
we elaborate a multidimensional evaluation index that integrates three dimensions that we deem essential: performance, inclusiveness, and excellence. This is a way of enriching the evaluation by incorporating some of the diversity that the countries exhibit regarding the distribution of outcomes into the different levels of proficiency.

The PISA establishes six levels of educational proficiency, parameterized in terms of the scores of the tests that students perform for each subject. The distribution of the students into those levels of competence provides rich information on the functioning of educational systems, which is not reflected in the average scores or the associated ranking of countries. A simple inspection of the data regarding the distribution of the students among those levels of competence shows that there is a large diversity, even between countries with similar average scores. Those differences are particularly relevant at the tails (the percentages of high and low performers). The outcome distributions on those levels of proficiency provide, therefore, important information on the structural features of the different educational systems. The OCDE pays an increasing attention to those outcome distributions (see for instance OCDE (2016, vol. I)); yet, it does not provide any concrete indicator that summarises it and permits a systematic comparison. The index we propose here incorporates part of that information into de determination of the educational achievements in a very simple way. ${ }^{2}$

It is worth noting that the OECD pinpoints levels 2 and 5 as the relevant goalposts to assess on the effectiveness of educational systems in getting minimal outcomes, on the one hand, and assessing high performance, on the other hand. We shall follow this convention here and will identify level 2 as a sort of poverty line for educational outcomes and level 5 as the threshold for excellence.

The Index we propose here has many features in common with the new Human Development Index (UNDP (2010)), even though it avoids some of its problems (see Herrero, Martínez \& Villar (2010), (2011)). It is a variant of some ideas developed in Villar (2013), aimed at taking into account different aspects of the outcome distributions.

Let us recall here that building a multidimensional index always involves three critical decisions: (a) The number and nature of the dimensions considered; (b) The choice of the variables that measure those dimensions; and (c) The selection of the aggregation formula. Those decisions, that are neither easy nor independent, determine the picture we obtain concerning the performance of the different educational systems. Simplifications and compromises are inevitable in that endeavour. Our way of dealing with this measure tries to meet three specific requirements that we think important for an index of this sort: (i) Simplicity: an index easy to understand and easy to use; (ii) Accessibility: an index that can be calculated directly from the published PISA reports, without requiring statistical abilities; and (iii) Flexibility: an index that can be adjusted and modified by the user to incorporate particular concerns.

We propose here a three-dimensional index of educational achievements that incorporates the distribution of the students' outcomes into the different levels of proficiency, while keeping the simplicity of real-valued measures. Those dimensions are: Performance, Inclusiveness and Excellence. Performance refers to the overall achievement of the students in a given society and

\footnotetext{
2 See Villar (2015) for a procedure to obtain a comparative of complete distributions in terms of a real valued indicator. Applications of a variant of this procedure can be found in Herrero \& Villar (2013), (2014), Herrero, Méndez \& Villar (2014), Villar (2014).
} 
is captured by the mean test scores of the aspect under consideration (science in this case). Inclusiveness refers to the capacity of an educational system to provide a minimal knowledge to the young. We shall use the percentage of students with at least proficiency level 2 to approach this aspect. Excellence deals with the extent of high performance and it is associated with the fraction of students equal or above level 5. Those three dimensions are certainly important and will be treated here symmetrically (see however the discussion below). ${ }^{3}$

Needless to say, the notions of performance, inclusiveness and excellence are complex and admit a number of interpretations. We are using those notions here as labels rather than as sound philosophical concepts, in order to give a more intuitive content to the variables we actually use. Be as it may, in view of the differences in the distribution of students by levels of proficiency, this index provides a more accurate estimate of the differences between educational systems because the spread of mean values is (artificially) very small and thus hides relevant information.

The paper is organised as follows. Section 2 presents the variables that approximate performance, inclusiveness and excellence, focussing on the field of science, which is the main subject of the 2015 wave. Section 3 introduces the Index of Educational Achievements. We compare the picture that this index provides and the one derived from computing average scores. A few final comments in Section 4 close the paper.

\section{A MULTIDIMENSIONAL APPROACH TO EDUCATIONAL ACHIEVEMENTS}

Let us recall here that, besides the average scores, the PISA classifies the students into six (actually seven) categories that approach the different skills that the students achieve, operationalized in term of ranges of the scores obtained by the students. Table 1 describes the score intervals for those levels and the percentage of students within each level in the OECD as a whole.

Table 1: Proficiency Levels in Science (PISA 2015)

\begin{tabular}{|l|l|l|l|l|l|}
\hline Proficiency levels & $<2$ & 2 & 3 & 4 & $5+$ \\
\hline Thresholds of the test scores & $<410$ & $411-484$ & $485-559$ & $560-633$ & $>633$ \\
\hline \% of OECD students & 23,5 & 25,4 & 25,6 & 17,8 & 7,6 \\
\hline
\end{tabular}

We shall describe now nature of the variables that enter the Index of Educational Achievements.

\section{Performance}

One of the assets of the PISA report is that it provides a unified scoring system to evaluate the performance of 15-year-old students in very different countries. The units of those scores are set with respect to the values obtained in the 2000 wave of the report, by taking a value of 500

\footnotetext{
${ }^{3}$ Needless to say one can think of other dimensions that are also relevant and/or of different degrees of relevance for those dimensions. Note, however, that the more dimensions we consider the more dependent becomes the index on the specific aggregation process and, in particular, on the weights we attach to those dimensions. Moreover, most of those dimensions tend to be rather elusive when it comes to give a precise content to their meaning and to select the variables that can measure them.
} 
for the average of the OECD Member States with a standard deviation of 100. We shall take the countries average test score as our measure of performance.

The variability of the average scores is relatively low, partly due to the protocol that defines the measurement units, with a coefficient of variation for the OECD of 0.055. Yet, the difference between top and bottom performers is huge: there are 122 score points of difference between Japan and Mexico, equivalent to three years of schooling.

Table 2 gives the values corresponding to the average score in science for the OECD countries. We normalise the values by setting the OECD mean equal to 1 in order to get an intuitive appraisal of the countries' differences.

Korea, Japan, Estonia and Finland are the countries with better performance while Mexico, Chile, Turkey and Greece occupy the lowest positions in the ranking. Sweden, Czech Republic and Spain represent the mean of the OECD countries (more detailed information on all participating countries for this and the following variables is provided in the Appendix).

Table 2: Performance in the OECD countries in science (PISA 2015) (OECD mean = 1)

\begin{tabular}{|l|r|}
\hline Countries & Average scores \\
\hline Australia & 1,034 \\
\hline Austria & 1,004 \\
\hline Belgium & 1,018 \\
\hline Canada & 1,070 \\
\hline Chile & 0,907 \\
\hline Czech Republic & 1,000 \\
\hline Denmark & 1,018 \\
\hline Estonia & 1,084 \\
\hline Finland & 1,076 \\
\hline France & 1,004 \\
\hline Germany & 1,033 \\
\hline Greece & 0,923 \\
\hline Hungary & 0,967 \\
\hline Iceland & 0,960 \\
\hline Ireland & 1,019 \\
\hline Israel & 0,946 \\
\hline Italy & 0,975 \\
\hline Japan & 1,092 \\
\hline Korea & 1,046 \\
\hline Latvia & 0,994 \\
\hline Luxembourg & 0,979 \\
\hline Mexico & 0,843 \\
\hline Netherlands & 1,032 \\
\hline New Zealand & 1,041 \\
\hline Norway & 1,011 \\
\hline Poland & 1,017 \\
\hline Portugal & 1,016 \\
\hline Slovak Republic & 0,935 \\
\hline Slovenia & 1,040 \\
\hline Spain & 1,000 \\
\hline Sweden & 1,001 \\
\hline Switzerland & 1,025 \\
\hline Turkey & 0,863 \\
\hline United Kingdom & 1,033 \\
\hline United States & \\
\hline & \\
\hline & \\
\hline
\end{tabular}




\section{Inclusiveness}

Inclusiveness is a dimension that refers to the capacity of an educational system to guarantee a minimum level of knowledge to all students. We take level 2 of proficiency to identify the students with sufficient knowledge to have good chances of integration in the labour market and social life. As mentioned before, the PISA takes precisely this level as the baseline of proficiency at which students begin to demonstrate the skills that will enable them to participate effectively and productively in life. ${ }^{4}$

According to the PISA 2015 report (vol. I, p. 60), "At Level 2, students are able to draw on everyday content knowledge and basic procedural knowledge to identify an appropriate scientific explanation, interpret data, and identify the question being addressed in a simple experimental design. They can use basic or everyday scientific knowledge to identify a valid conclusion from a simple data set. Level 2 students demonstrate basic epistemic knowledge by being able to identify questions that can be investigated scientifically." There is evidence, particularly longitudinal studies developed in Australia, Canada, Denmark and Switzerland, showing that students who perform below Level 2 often face severe disadvantages in their transition into higher education and the labour force in subsequent years. Consequently, "the proportion of students who perform below this baseline proficiency level thus indicates the degree of difficulty countries face in providing their populations with a minimum level of competencies." (cf. OECD (2014, vol. I, p. 68)).

We can think of the fraction of students below Level 2 as a measure of educational poverty (a simple head count ratio). Its complement, the fraction of the students with level of proficiency equal or above level 2, can therefore be regarded as a measure of inclusiveness. Note that this variable, simple as it is, involves equity and efficiency features. From an equity perspective this variable tells us about the share of students who are not under the educational poverty threshold. The equity significance of this measure is enhanced by the well-established correlation between educational outcomes and family background. From an efficiency viewpoint, this variable tells us the percentage of 15 year-old students who succeed in getting a minimal stock of human capital, provided by the educational system.

The diversity of educational systems regarding inclusion is large, with a coefficient of variation that is twice that of the average scores the OECD countries (note though that the CV of the students below level 2 is much larger, about eight times that of the average scores).

The most inclusive countries within the OECD are Estonia and Japan, with more than $90 \%$ of the population above level 2. Mexico and Turkey are those with lower values, even if we disregard the fact that a large proportion of their 15-year old people have already left the school. Table 3 below shows the normalised values of this variable for the OECD countries.

\footnotetext{
${ }^{4}$ This convention is not universal, though. Some authors adopt level 3 as the baseline (e.g. Nonoyama-Tarumi \& Willms (2010).
} 
Table 3: Inclusiveness in the OECD Countries in Science (PISA 2015) (Mean OECD = 1)

\begin{tabular}{|l|r|}
\hline Countries & Inclusiveness \\
\hline Australia & 1,046 \\
\hline Austria & 1,005 \\
\hline Belgium & 1,018 \\
\hline Canada & 1,128 \\
\hline Chile & 0,827 \\
\hline Czech Republic & 1,006 \\
\hline Denmark & 1,067 \\
\hline Estonia & 1,157 \\
\hline Finland & 1,123 \\
\hline France & 0,989 \\
\hline Germany & 1,053 \\
\hline Greece & 0,854 \\
\hline Hungary & 0,939 \\
\hline Iceland & 0,948 \\
\hline Ireland & 1,075 \\
\hline Israel & 0,871 \\
\hline Italy & 0,975 \\
\hline Japan & 1,147 \\
\hline Korea & 1,086 \\
\hline Latvia & 1,051 \\
\hline Luxembourg & 0,940 \\
\hline Mexico & 0,662 \\
\hline Netherlands & 1,034 \\
\hline New Zealand & 1,048 \\
\hline Norway & 1,032 \\
\hline Poland & 1,062 \\
\hline Portugal & 1,048 \\
\hline Slovak Republic & 0,879 \\
\hline Slovenia & 1,079 \\
\hline Spain & 1,037 \\
\hline Sweden & 0,995 \\
\hline Switzerland & 1,034 \\
\hline Turkey & 0,704 \\
\hline United Kingdom & 1,048 \\
\hline United States & 1,011 \\
\hline
\end{tabular}

\section{Excellence}

Excellence is a dimension that captures the extent of high performance in the population of 15year old students. It refers to the thickness of the right hand tail of the distribution of the students into the different levels of proficiency. The underlying idea is that the fraction of students with high levels of performance is a predictor of those who will get higher education and more likely to exert social leadership. 
One of the simplest ways of having a proxy of the quality of an educational system is taking the share of the students in the upper levels of proficiency (levels 5 and 6 of the PISA study -see Table 1 above-). According to PISA: "At Level 5, students can use abstract scientific ideas or concepts to explain unfamiliar and more complex phenomena, events and processes involving multiple causal links. They are able to apply more sophisticated epistemic knowledge to evaluate alternative experimental designs and justify their choices and use theoretical knowledge to interpret information or make predictions. Level 5 students can evaluate ways of exploring a given question scientifically and identify limitations in interpretations of data sets including sources and the effects of uncertainty in scientific data. (OECD (2016), vol. I, p. 60)). ${ }^{5}$

We take as a measure of excellence the share of the students in levels of competence 5 and 6 . This variable exhibits an extremely high variability, with a coefficient of variation of 0.5 , nine times the coefficient of variation of the average scoring for the OECD countries. The countries with best outcomes regarding excellence are Japan and Finland, with more than 14\% of its population in or above level 5. In the opposite side we find Mexico and Turkey, with less than $1 \%$ of its population in that category. Table 4 shows the data for the OECD countries with respect to this variable.

5 Concerning level 6, PISA specifies: "At Level 6, students can draw on a range of interrelated scientific ideas and concepts from the physical, life and earth and space sciences and use content, procedural and epistemic knowledge in order to offer explanatory hypotheses of novel scientific phenomena, events and processes or to make predictions. In interpreting data and evidence, they are able to discriminate between relevant and irrelevant information and can draw on knowledge external to the normal school curriculum. They can distinguish between arguments that are based on scientific evidence and theory and those based on other considerations. Level 6 students can evaluate competing designs of complex experiments, field studies or simulations and justify their choices." (Ibid). 
Table 4: Excellence in Science at the OECD Countries (PISA 2015)

(OECD mean $=1)$

\begin{tabular}{|l|r|}
\hline Countries & Excellence \\
\hline Australia & 1,455 \\
\hline Austria & 1,000 \\
\hline Belgium & 1,169 \\
\hline Canada & 1,610 \\
\hline Chile & 0,156 \\
\hline Czech Republic & 0,948 \\
\hline Denmark & 0,909 \\
\hline Estonia & 1,753 \\
\hline Finland & 1,857 \\
\hline France & 1,039 \\
\hline Germany & 1,377 \\
\hline Greece & 0,273 \\
\hline Hungary & 0,597 \\
\hline Iceland & 0,494 \\
\hline Ireland & 0,922 \\
\hline Israel & 0,753 \\
\hline Italy & 0,532 \\
\hline Japan & 1,987 \\
\hline Korea & 1,377 \\
\hline Latvia & 0,494 \\
\hline Luxembourg & 0,896 \\
\hline Mexico & 0,013 \\
\hline Netherlands & 1,442 \\
\hline New Zealand & 1,662 \\
\hline Norway & 1,039 \\
\hline Poland & 0,948 \\
\hline Portugal & 0,961 \\
\hline Slovak Republic & 0,468 \\
\hline Slovenia & 1,377 \\
\hline Spain & 0,649 \\
\hline Sweden & 1,104 \\
\hline Switzerland & 1,273 \\
\hline Turkey & 039 \\
\hline United Kingdom & 1,416 \\
\hline United States & \\
\hline & \\
\hline
\end{tabular}




\section{THE INDEX OF EDUCATIONAL ACHIEVEMENTS (IEA)}

The Index of Educational Achievements, IEA for short, is a summary measure of the educational attainments in the three specific dimensions presented above: performance, inclusiveness and excellence. The index consists of the geometric mean of the normalized values of the variables that approximate those dimensions.

Consider a society $j$ (typically a country, but also a region or even a school) in a given period (year 2015 in our case) and suppose we have the relevant data on the variables that approach those three dimensions for of the target population. Let $P_{j}, I_{j}, E_{j}$ denote those values. The Index of Educational Achievements is given by:

$$
I E A_{j}\left(P_{j}, I_{j}, E_{j}\right)=\left(\frac{P_{j}}{P_{0}} \times \frac{I_{j}}{i_{0}} \times \frac{E_{j}}{E_{0}}\right)^{1 / 3}=\sqrt[3]{p_{j} \times i_{j} \times e_{j}}
$$

where $P_{0}, I_{0}, E_{0}$ are some reference values selected so that the resulting normalized variables, $p$, $i, e$, are easy to interpret.

The normalization is convenient in order to set the values of the different dimensions into some type of common units. We take here as reference values the OECD average of each variable, so that one hundred times $x$ tells us the percentage of the OECD average that this variable represents, for $x=p$, $i, e$. All normalised variables represent, therefore, shares on the OECD average and their values are easily understandable. This normalisation has the convenient property that a change of the reference values will affect neither the ranking that the IEA produces among the different countries nor the relative valuations of any two societies.

The geometric mean is a centrality measure that exhibits better properties than the arithmetic mean, as it is an aggregator that penalises the dispersion of its components. That is, getting high values of the index requires doing well in all the three dimensions. Moreover, the geometric mean is a common centrality measure with an intuitive interpretation that many people can understand. ${ }^{6}$

The overall educational achievements of the OECD countries, as measured by the Index of Educational Achievements, exhibit much more variability than the average PISA scores. The IEA has a coefficient of variation of about five times that of the average scores $(0.26$ with respect to 0.055).

The different behaviour of the average test scores (performance) and the IEA, in the OECD countries, is well illustrated in Figure 1, where we present the shape of the distribution, ordering the countries according to their performance values (from top to bottom). Figure 1 points out two main aspects. First, that the variability is much higher for the EDI. Second, that there are also many changes in the ranking (that appear as peaks in the EDI line).

\footnotetext{
6 The geometric mean can be characterized in terms of reasonable assumptions that adjust well to this context.
} See for instance Foster et al (2005), Seth (2009, 2010), or Herrero, Martínez \& Villar $(2010,2011)$. 
Figure 1: Performance and IEA in the OECD Countries (Science, PISA 2015)

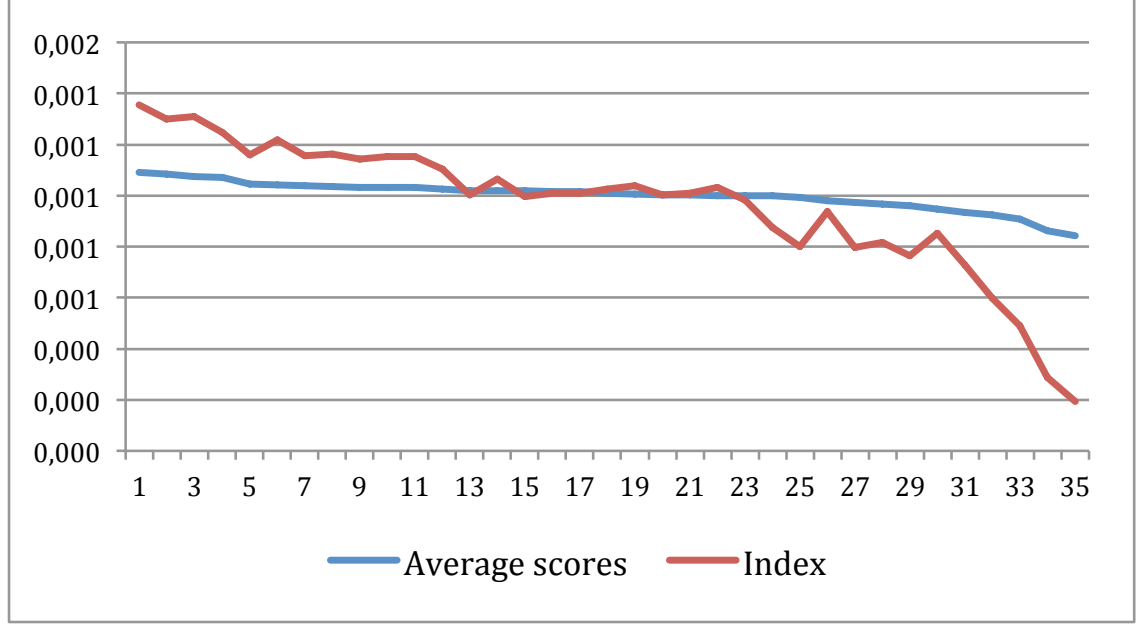

The last column of Table 5 provides the values of the IEA for the OECD countries. The other columns describe the position that each country occupies in the ranking of the individual variables that conform the index as well as the ranking of the IEA. We observe that there are countries that exhibit very different positions in the ranking of the constituent variables (e.g. Denmark and Sweden), while others keep a rather homogeneous ranking. 
Table 5: Index of Educational Achievements for the OECD (mean OECD = 1) and Ranking of the Constituent Variables

\begin{tabular}{|c|c|c|c|c|c|}
\hline & $\begin{array}{l}\text { Ranking } \\
\text { Performance }\end{array}$ & $\begin{array}{l}\text { Ranking } \\
\text { Inclusion }\end{array}$ & $\begin{array}{l}\text { Ranking } \\
\text { Excellence }\end{array}$ & \begin{tabular}{|l} 
Ranking \\
IEA
\end{tabular} & IEA score \\
\hline Australia & 8 & 15 & 6 & 6 & 1,163 \\
\hline Austria & 20 & 23 & 18 & 21 & 1,003 \\
\hline Belgium & 14 & 20 & 13 & 13 & 1,066 \\
\hline Canada & 4 & 3 & 5 & 4 & 1,248 \\
\hline Chile & 33 & 33 & 33 & 33 & 0,489 \\
\hline Czech Republic & 23 & 22 & 20 & 23 & 0,984 \\
\hline Denmark & 15 & 8 & 23 & 22 & 0,996 \\
\hline Estonia & 2 & 1 & 3 & 3 & 1,300 \\
\hline Finland & 3 & 4 & 2 & 2 & 1,309 \\
\hline France & 21 & 25 & 16 & 17 & 1,010 \\
\hline Germany & 10 & 10 & 9 & 11 & 1,144 \\
\hline Greece & 32 & 32 & 32 & 32 & 0,599 \\
\hline Hungary & 28 & 29 & 27 & 27 & 0,816 \\
\hline Iceland & 29 & 27 & 29 & 30 & 0,766 \\
\hline Ireland & 13 & 7 & 22 & 20 & 1,003 \\
\hline Israel & 30 & 31 & 25 & 26 & 0,853 \\
\hline Italy & 27 & 26 & 28 & 29 & 0,797 \\
\hline Japan & 1 & 2 & 1 & 1 & 1,355 \\
\hline Korea & 5 & 5 & 10 & 7 & 1,161 \\
\hline Latvia & 25 & 11 & 30 & 28 & 0,802 \\
\hline Luxembourg & 26 & 28 & 24 & 24 & 0,938 \\
\hline Mexico & 35 & 35 & 35 & 35 & 0,194 \\
\hline Netherlands & 11 & 17 & 7 & 9 & 1,154 \\
\hline New Zealand & 6 & 12 & 4 & 5 & 1,220 \\
\hline Norway & 18 & 19 & 17 & 16 & 1,027 \\
\hline Poland & 16 & 9 & 21 & 18 & 1,008 \\
\hline Portugal & 17 & 13 & 19 & 19 & 1,008 \\
\hline Slovak Republic & 31 & 30 & 31 & 31 & 0,727 \\
\hline Slovenia & 7 & 6 & 11 & 8 & 1,156 \\
\hline Spain & 24 & 16 & 26 & 25 & 0,876 \\
\hline Sweden & 22 & 24 & 14 & 15 & 1,032 \\
\hline Switzerland & 12 & 18 & 12 & 12 & 1,105 \\
\hline Turkey & 34 & 34 & 34 & 34 & 0,287 \\
\hline United Kingdom & 9 & 14 & 8 & 10 & 1,153 \\
\hline United States & 19 & 21 & 15 & 14 & 1,040 \\
\hline
\end{tabular}


These data show that the IEA allows uncovering relevant differences among the countries with respect to some key features of the educational systems. Inclusiveness and Excellence exhibit patterns of behaviour that can be very different in pair-wise comparisons and shed light on the nature of the differential achievements. Indeed, the analysis of the distribution of the different variables is worth on its own, as it provides valuable information on the differences of the countries with respect to in the selected dimensions.

If we compute the correlation between each pair of variables within the IEA we observe that they are always positive and very high. Table 6 below provides the corresponding coefficients of correlation. We observe that the highest coefficient corresponds to that relating performance and inclusiveness. This points out, once more, that reducing scholastic failure is the main way of improving average scores (e.g. Willms (2006)). This is important because it implies that improving inclusiveness is not only an equity measure but also an efficiency one. Performance and excellence have also a very high correlation, most notably in OECD countries. The correlation between inclusiveness and excellence is also very high indicating that there is no trade-off between both variables. That is, getting a more inclusive society does not imply renouncing to the excellence; on the contrary, both variables go hand in hand together.

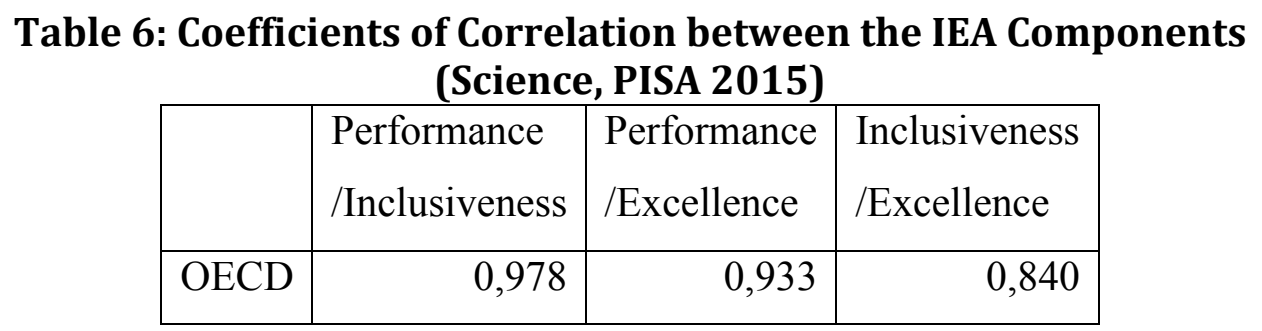

\section{FINAL COMMENTS}

We have presented in this paper a proposal to evaluate the educational achievements of the countries, out of the data in the PISA, aimed at incorporating some relevant aspects that are not captured by the average test scores (inclusiveness and excellence). The Index of Educational Achievements (IEA) is simply the geometric mean of the normalized values of the variables that approach those dimensions. The data show that the information provided by this construct helps evaluating systematically the students' results with a much large discrimination power. This may help policy makers identifying the key targets to look for improvements.

We have mentioned in the Introduction that we aimed at the construction of an index easy to handle and interpret, accessible, and flexible. The formula of the index and the choice of variables that measure the different dimensions ensure the first of these constraints. Accessibility is guaranteed by the OECD handy webpage, which offers the data in a readily usable format (standard spread-sheets). Flexibility refers to the possibility that any interested person, not necessarily a specialist, can perform alternative evaluation exercises by simple manipulations of those data (much in the spirit of what is proposed in the OECD Better Life Index).

There are four specific concerns, regarding flexibility, that this construction permits handling. The first one is the possibility of using different weights for the different dimensions. That is, people may have different perceptions about how important is performance, inclusiveness and excellence, and may be willing to know how countries fare under different configurations of 
those weights. This can be easily done using differential powers, to express our judgement of the relevance of those aspects. That is, using the formula:

$$
\begin{gathered}
I E A=p^{\alpha} \times i^{\beta} \times e^{\gamma} \\
\text { with } \alpha+\beta+\gamma=1 .
\end{gathered}
$$

The second one deals with the incorporation of additional dimensions or the use of composite ones. This applies in particular to using not only the results in science $(s)$ but also those in reading literacy $(r)$ and mathematics $(m)$. Given the properties of the geometric mean, this can be achieved by simply taking the geometric mean of the corresponding geometric means. That is:

$$
I E A=\sqrt[3]{\left(p_{m} \times p_{r} \times p_{s}\right)^{1 / 3} \times\left(i_{m} \times i_{r} \times i_{s}\right)^{1 / 3} \times\left(e_{m} \times e_{r} \times e_{s}\right)^{1 / 3}}
$$

(and, of course, one can combine this generalisation with that consisting of given different weights to the different dimensions discussed above).

The third one refers to the very nature of the index. The geometric mean can be replaced by the arithmetic mean when the disparities between the (normalised) variables is deemed irrelevant or when there are countries for which some variable is very close to zero (as it happens with excellence in some Partner countries).

The last concern involves the adjustment of the index by the shares of students attending school. The PISA results evaluate the knowledge of those students attending school, rather than that of 15-year old people. This difference turns out to be very important in some countries in which more than a quarter of the 15-year old population has abandoned the educational system and are, therefore, out of the sample (Mexico and Turkey in particular, within the OECD). As there is no information on that part of the population it is not clear how to adjust the data to take into account those different participation rates. A simple (yet arbitrary) way of introducing that element into our analysis would be to add $1 / 2$ of the young who have abandoned the school at 15 to the population below level 2. In the absence of information on this population, assuming that one half have not reached level 2 is a prudent proposal. This change in the IEA can be easily done out the tables provided in the PISA report.

\section{Acknowledgements}

This work was partly done while I was visiting the OECD as a Thomas J. Alexander Fellow. Thanks are due to the Programme for the opportunity of doing this research. I would like to thank Pablo Zoido for his helpful comments. 


\section{REFERENCES}

Checchi, D. \& Peragine, V. (2005), Regional Disparities and Equality of Opportunity: The Case of Italy, IZA working paper 1874.

Ferreira, F.H.G. \& Ginoux, J. (2011), The Measurement of Educational Inequality: Achievement and Opportunity, IZA working paper no 6161.

Foster, J.E., López-Calva, L.F. and Székely, M. (2005), Measuring the Distribution of Human Development: Methodology and an Application to Mexico, Journal of Human Development and Capabilities, 6: 5-29. Herrero, C., Martínez, R. \& Villar, A. (2010), Multidimensional Social Evaluation. An Application to the Measurement of Human Development, Review of Income and Wealth, 56 : 483-497.

Herrero, C., Martínez, R. \& Villar, A. (2011), A New² Human Development Index, Journal of Human Development and Capabilities, forthcoming.

Lefranc, A., Pistolesi, N. \& Trannoy, A. (2006), Equality of Opportunity: Definitions and Testable Conditions, with an Application to France, ECINEQ society, working paper 53.

OECD (2016), PISA 2015 Results (Vol. I). Excellence and Equity in Education, OECD Publishing, Paris,

Peragine, V. \& Serlenga, L. (2007), Equality of Opportunity for Higher Education in Italy, in J. Bishop and B.

Zheng (eds.), Research in Economic Inequality, vol. 12.

Seth, S. (2009), Inequality, Interactions, and Human Development, Journal of Human Development and Capabilities, $10: 375-396$.

Seth, S. (2010), A Class of Association Sensitive Multidimensional Welfare Indices, mimeo, Vanderblit University. United Nations Development Program (2010), The Real Wealth of Nations: Pathways to Human Development.

\section{APPENDIX: THE IEA AND ITS COMPONENTS FOR PARTNER COUNTRIES}

We present here the data corresponding to the Partner countries in two different formats, which may be of interest. Table A.1 contains the IEA and its components, elaborated so that they are fully comparable with the OECD results. Note that there appear some values equal to zero due to the negligible fraction of students with proficiency equal or above 5 . A zero in one of the variables for a given country drives its evaluation to zero, no matter how it does in the other dimensions, due to the multiplicative nature of the formula. Table A.2 also contains information on the Index of Educational Achievements and its components, but now the values have been normalised with respect to the mean of each variable within this group of countries, and denoted by IEA*. Note that those values are not comparable with those of the OECD any more. Besides, we also provide the arithmetic mean of those normalised variable in order to avoid the problem of the zeros. This amounts to ignoring the disparities in the variables that compose the index for each country. 
Table A.1: The IEA and its Components for Partner Countries

\begin{tabular}{|l|r|r|r|l|}
\hline & Performance & Inclusion & Excellence & IEA \\
\hline Albania & 0,867 & 0,740 & 0,052 & 0,322 \\
\hline Algeria & 0,762 & 0,371 & 0,000 & 0,000 \\
\hline Brazil & 0,813 & 0,551 & 0,091 & 0,344 \\
\hline B-S-J-G (China) & 1,050 & 1,063 & 1,766 & 1,254 \\
\hline Bulgaria & 0,904 & 0,788 & 0,377 & 0,645 \\
\hline Chinese Taipei & 1,080 & 1,112 & 2,000 & 1,339 \\
\hline Colombia & 0,843 & 0,647 & 0,052 & 0,305 \\
\hline Costa Rica & 0,851 & 0,680 & 0,013 & 0,196 \\
\hline Croatia & 0,964 & 0,957 & 0,506 & 0,776 \\
\hline Cyprus & 0,877 & 0,735 & 0,208 & 0,512 \\
\hline Dominican Republic & 0,673 & 0,181 & 0,000 & 0,000 \\
\hline FYROM & 0,778 & 0,471 & 0,026 & 0,212 \\
\hline Georgia & 0,834 & 0,624 & 0,117 & 0,393 \\
\hline Hong Kong (China) & 1,061 & 1,150 & 0,961 & 1,055 \\
\hline Indonesia & 0,818 & 0,558 & 0,013 & 0,181 \\
\hline Jordan & 0,829 & 0,637 & 0,026 & 0,239 \\
\hline Kosovo & 0,768 & 0,410 & 0,000 & 0,000 \\
\hline Lebanon & 0,784 & 0,475 & 0,052 & 0,268 \\
\hline Lithuania & 0,964 & 0,956 & 0,545 & 0,795 \\
\hline Macao (China) & 1,072 & 1,166 & 1,195 & 1,143 \\
\hline Malta & 0,943 & 0,857 & 0,987 & 0,927 \\
\hline Moldova & 0,868 & 0,734 & 0,091 & 0,387 \\
\hline Montenegro & 0,834 & 0,622 & 0,065 & 0,323 \\
\hline Peru & 0,805 & 0,527 & 0,013 & 0,177 \\
\hline Qatar & 0,847 & 0,637 & 0,221 & 0,492 \\
\hline Romania & 0,882 & 0,780 & 0,091 & 0,397 \\
\hline Russia & 0,987 & 1,038 & 0,481 & 0,790 \\
\hline Singapore & 1,127 & 1,147 & 3,143 & 1,596 \\
\hline Thailand & 0,855 & 0,676 & 0,065 & 0,335 \\
\hline Trinidad and Tobago & 0,688 & 0,182 & 0,476 \\
\hline Tunisia & 0,433 & 0,000 & 0,000 \\
\hline United Arab Emirates & 0,739 & 0,364 & 0,620 \\
\hline Uruguay & 0,751 & 0,169 & 0,482 \\
\hline Viet Nam & & & & \\
\hline
\end{tabular}


Table A.2: The IEA* and its Components for Partner Countries

\begin{tabular}{|c|c|c|c|c|c|}
\hline & Performance & Inclusion & Excellence & $\begin{array}{c}\text { Arithmetic } \\
\text { mean }\end{array}$ & IEA* \\
\hline Albania & 0,975 & 1,005 & 0,133 & 0,705 & 0,508 \\
\hline Algeria & 0,858 & 0,503 & 0,000 & 0,454 & 0,000 \\
\hline Brazil & 0,915 & 0,748 & 0,233 & 0,632 & 0,543 \\
\hline B-S-J-G (China) & 1,182 & 1,445 & 4,533 & 2,387 & 1,978 \\
\hline Bulgaria & 1,018 & 1,071 & 0,967 & 1,018 & 1,017 \\
\hline Chinese Taipei & 1,215 & 1,510 & 5,133 & 2,620 & 2,112 \\
\hline Colombia & 0,949 & 0,879 & 0,133 & 0,654 & 0,481 \\
\hline Costa Rica & 0,958 & 0,924 & 0,033 & 0,638 & 0,309 \\
\hline Croatia & 1,085 & 1,300 & 1,300 & 1,228 & 1,224 \\
\hline Cyprus $^{2}$ & 0,988 & 0,998 & 0,533 & 0,840 & 0,807 \\
\hline Dominican Republic & 0,757 & 0,247 & 0,000 & 0,335 & 0,000 \\
\hline FYROM & 0,876 & 0,640 & 0,067 & 0,527 & 0,334 \\
\hline Georgia & 0,939 & 0,848 & 0,300 & 0,696 & 0,620 \\
\hline Hong Kong (China) & 1,195 & 1,562 & 2,467 & 1,741 & 1,664 \\
\hline Indonesia & 0,920 & 0,759 & 0,033 & 0,571 & 0,286 \\
\hline Jordan & 0,933 & 0,866 & 0,067 & 0,622 & 0,378 \\
\hline Kosovo & 0,864 & 0,557 & 0,000 & 0,474 & 0,000 \\
\hline Lebanon & 0,882 & 0,645 & 0,133 & 0,554 & 0,423 \\
\hline Lithuania & 1,085 & 1,298 & 1,400 & 1,261 & 1,254 \\
\hline Macao (China) & 1,207 & 1,584 & 3,067 & 1,953 & 1,803 \\
\hline Malta & 1,061 & 1,164 & 2,533 & 1,586 & 1,463 \\
\hline Moldova & 0,977 & 0,997 & 0,233 & 0,736 & 0,610 \\
\hline Montenegro & 0,939 & 0,845 & 0,167 & 0,650 & 0,509 \\
\hline Peru & 0,906 & 0,716 & 0,033 & 0,552 & 0,278 \\
\hline Qatar & 0,953 & 0,866 & 0,567 & 0,795 & 0,776 \\
\hline Romania & 0,993 & 1,060 & 0,233 & 0,762 & 0,626 \\
\hline Russia & 1,111 & 1,410 & 1,233 & 1,252 & 1,246 \\
\hline Singapore & 1,268 & 1,559 & 8,067 & 3,631 & 2,517 \\
\hline Thailand & 0,962 & 0,919 & 0,167 & 0,683 & 0,528 \\
\hline Trinidad and Tobago & 0,969 & 0,934 & 0,467 & 0,790 & 0,751 \\
\hline Tunisia & 0,882 & 0,588 & 0,000 & 0,490 & 0,000 \\
\hline United Arab Emirates & 0,997 & 1,003 & 0,933 & 0,978 & 0,977 \\
\hline Uruguay & 0,994 & 1,021 & 0,433 & 0,816 & 0,760 \\
\hline Viet Nam & 1,198 & 1,622 & 2,767 & 1,862 & 1,752 \\
\hline
\end{tabular}

